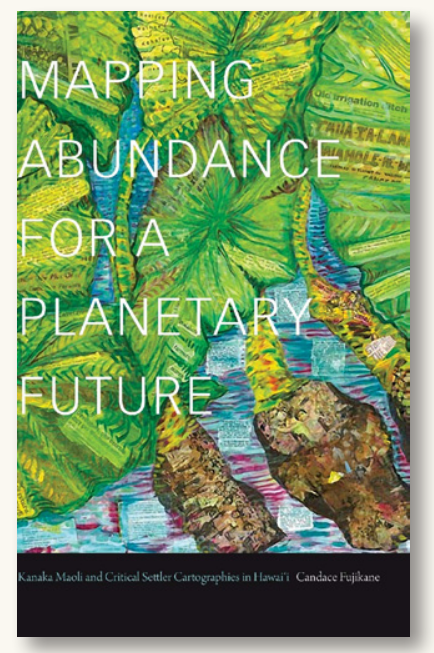

\title{
MAPPING ABUNDANCE FOR A PLANETARY FUTURE: KANAKA MAOLI AND CRITICAL SETTLER CARTOGRAPHIES IN HAWAI'I
}

\author{
By Candace Fujikane
}

Duke University Press, 2021

279 pages, with maps, artwork, and photography

Softcover: \$27.95, ISBN 978-1-4780-1 168-2

Review by: Daniel G. Cole, Smithsonian Institution

I CANNOT BEGIN THIS REVIEW without addressing the book's title. Because so little of this book relates to planetary affairs and is instead concerned with issues of environmental justice and the conflicting beliefs, practices, and cartographies (both cognitive and practical) of the Kanaka Maoli (or Native Hawaiians) and the immigrant settlers, I would have suggested that the subtitle Kanaka Maoli and Critical Settler Cartographies in Hawai' $i$ was a complete title in itself. The author is a professor of English at the University of Hawai' $i$ and appears well versed in both colonial/Native Hawaiian history and in current local affairs. Her extensive use of Hawaiian words, however, while no doubt appropriate, can make for heavy reading for anyone unfamiliar with the Indigenous terms. I was surprised that she didn't include a Hawaiian/English glossary, something that the Native Hawaiian cartographer Renee Pualani Louis provided in her 2017 book, Kanaka Hawai'i Cartography.

In her Introduction, Fujikane quickly establishes a clear dichotomy between Indigenous and capitalist cartographies, writing that whereas "The procession of mo'o ${ }^{1}$ teaches us cartographic principles of the pilina (connectedness) of the myriad ecosystems," the "cartographies of capital are processes of mapmaking that often rely on insistence rather than substance, on force and will rather than on ground truths." In contrast to the former, she argues that the latter "cartographies do not therefore merely depict the systems of a planet laid waste ... but are themselves a primary driving force of climate change" (3). She further argues that "cartography as a methodology is critical to growing intimate relationships with 'aina (land and waters who feed $)^{2}$ in ways necessary to our planetary future" and that "mapping abundance is a profoundly decolonial act" (4), in contrast to cartographies of capital that "enclose and domesticate Indigenous places" (5). The one map appearing in this section is O'abu: Pre-Mabele Moku and Ahupua'a (20), from the Hawaiian Studies Institute (1987), showing the island divided into areas of access to resources. She then extends the cartographic work of Beamer and Duarte (2009), Beamer and Gonschor (2014), and Louis (2017) by incorporating Indigenous cognitive cartography with public participation mapping in a pursuit of environmental justice.

In Chapter 1, "Mo'o'aina as Cartographic Method," the author complains about a developer's plans to desecrate Maui, and focuses on their use of maps to dismember the land into small, fragmented plots that can later be rezoned for light industry. The developers, following the lead of many land speculators on the American mainland, begin by declaring lands not "productively" in use to be "wasteland" in order acquire or steal legal control over them. They then use gridded land divisions to explode a spot that is special to Native Hawaiians into isolated fragments, in a manner much like the way the United States Public Land

1. The mo'o are mystical beings, involved in a procession across the landscape.

2. 'Aina are those lands and waters from which a person draws sustenance. 
Survey System (PLSS) was used to disenfranchise mainland Native American residents. Research carried out by Fujikane and her compatriots on documents identifying lands formerly farmed by Native Hawaiians, as well as on a number of historical maps (cropped portions of which are shown on pages 47 and 58), amply illustrate the way the neocolonial settlers used artificial lines to divide the landscape, ignoring and denying its interconnectedness.

Fujikane foregrounds the need for Kanaka Maoli (Native Hawaiians) and empathetic settlers to look beyond conventional two-dimensional maps in Chapter 2, "Maps in Motion," calling for maps to be set into motion by leveraging all four dimensions of space and time. By way of illustration, she discusses some good examples of the use of public participatory cartography to deal with various environmental injustices inflicted upon Native Hawaiians by military, commercial, industrial, and agricultural interests. She cites cartographic work by unidentified "Concerned Elders" that uses "the land itself as a map to render visible the abundance of the valley" (84) and contrasts it with the use of aerial photos and maps by commercial interests to differentiate "highly productive" from "not productive" lands solely by the presence of irrigation (82-83).

For Chapter 3, "Mo'oinanea's Waterways on Mauna a Wakea," Fujikane delves into the history and repercussions surrounding construction of the 13 observatories currently on the peak of the dormant volcano Mauna Kea, also known as Mauna a Wakea. The discussion contrasts Hawaiian beliefs, rooted in intergenerational knowledge, about the sacredness of the landscape, with the almost complete disregard with which mainlanders have treated these concerns. To the American surveyors since the late 1800s, and to the telescope planners since the 1960s, Mauna Kea was, and remains, an empty wasteland, and it is notable that no treaty or consent to transfer the land was ever made (or even considered necessary), and even today no actual title to the land exists. It is as if, officially, Mauna Kea exists in a vacuum. This limbo is illustrated by a schematic map (105) from the University of Hawai' $i$ that ignores the local hydrogeology and shows only one side of the mountain.

Chapter 4, "Kupuna Pohaku on Mauna a Wakea," recounts the period from the 1893 US invasion and overthrow of Queen Lili 'uokalani, through the 1959 declaration of statehood (with the attendant transfer of trust land from federal to state control), up to the present. It features a description of the vigorous, nonviolent protests that began in 2014 to oppose the construction of the Thirty Meter Telescope (TMT) on Mauna Kea. While the TMT Conservation District Use Application included maps that show the site as "empty space," these are contradicted by an intricate "star" map (Plate 11) that incorporates all of the many sites included in an archaeological inventory of historic shrines surrounding the mountain. One ethnologist noted that "a fundamental problem in archaeological studies [used by organizations like TMT]; the failure to evaluate individual sites as parts of regional complexes" (126).

In Chapter 5, "Vertical Maps of Subterranean Waters in Kalihi," the author tells us that the "the US Navy stores 187 million gallons of jet fuel only one hundred feet above the Southern O'ahu Basal Aquifer” (144-145). From the chapter title, a tradition-minded cartographic reader might expect to see a 3D map of the hydrogeology of O'ahu. Instead, Fujikane provides a storyboard sketch map (172) of the waters that feed Ke'ehi (a large lagoon in west Honolulu, near Pearl Harbor) which gives an Indigenous view of the hydro-environment of a portion of O'ahu.

Near the beginning of Chapter 6, "Mo'o'Aina Cascades in Waiahole and He'eia," is a reference to Plate 13, which is a photo of flowering shrubs alongside a road. Because the plate is titled "Mapping Hau (mea)," a reader might think that this photo is mislabeled, or perhaps the caption refers to a field mapping location. Unfortunately, Fujikane does not provide much of an explanation. Somewhat less mysteriously, she presents the history of water diversion on O'ahu: in 1916 for commercial sugar production (ending the Indigenous practice of kalo [taro] farming); in 1973 as part of an attempt to evict farmers for residential development; and finishing with a 1993 proposal to restore some diverted waters. This last agreement ended with nearly half of the diverted waters being returned in 1995, allowing for the restoration of historical fish ponds. The chapter ends with a discussion of the importance of coral for the health of local marine life. In this chapter, she provides three examples of cartographic art by Mealaaloha Bishop (Figure 6.3 on 186, and Plates 14 and 15) with watersheds and streams symbolized as the veins of kalo leaves, and with numerous place names.

The Conclusion provides a painting (209) of the demigod "Maui, the great navigator of the Pacific, wayfinding according to the laws of the akua, looking to the elemental 
forms and their signs for guidance" (210). Fujikane also gives us a reduced copy of Ashley Hunt's poster map $A$ World Map: In Which We See... (Plate 16) describing it as "a dazzling and intricate schematic of globalization and the implosive demise of capital" (211). Unfortunately, it's too small to read and no close-ups are given.

Overall, in spite of the problems noted above, Fujikane provides an interesting presentation on the environmental issues facing Native Hawaiians, and on how they perceive their environment in contrast to the controlling government and settler activities. I don't know if I can recommend this book to cartographers, but it surely can be recommended to anyone working on environmental justice concerns with Indigenous peoples. If she follows this book up with a later edition, as I hope she does, I recommend that she include a glossary and some close-up copies of the maps. I also suggest she put some more thought into the title. Lastly, I would be interested in seeing her reaction to the recent (29 June 2021) webinar on the management of Papahānaumokuākea Marine National Monument, hosted by National Oceanic and Atmospheric Administration (NOAA)'s Office of Hawaiian Affairs. For information on this, see the websites: New guidance document to integrate Native Hawaiian culture into management of Papahanaumokuakea and Integrating Native Hawaiian culture into management of Papahanaumokuakea.

\section{REFERENCES}

Beamer, Kamanamaikalani, and T. Ka'eo Duarte. 2009. "I palapala no ia aina: Documenting the Hawaiian Kingdom - A Colonial Venture?” Journal of Historical Geography 35 (1): 66-86. https://doi.org/10.1016/j. jhg.2008.04.002.

Beamer, Kamanamaikalani, and Lorenz Gonschor. 2014. "Toward an Inventory of Ahupua'a in the Hawaiian Kingdom: A Survey of Nineteenth and Early Twentieth Century Cartographic and Archival Records of the Islands of Hawai' 'i." Hawaiian Journal of History 48 (1): 53-87.

Louis, Renee Pualani. 2017. Kanaka Hawai i Cartography. Corvallis, OR: Oregon State University Press. 